\title{
Negative and positive congruence effects in letters and shapes
}

\author{
CEES VAN LEEUWEN \\ Brain Science Institute, RIKEN, Wako-Shi, Japan \\ and University of Sunderland, Sunderland, England \\ and \\ THOMAS LACHMANN \\ University of Leipzig, Leipzig, Germany, \\ and Brain Science Institute, RIKEN, Wako-Shi, Japan
}

\begin{abstract}
In six experiments in which a binary classification task was used, letter and nonletter (geometrical shapes, pseudoletters, or rotated letters) targets were presented either in isolation or surrounded by a geometrical shape. The surrounding shape could be congruent or incongruent with the target. When the classification required a distinction between letters and nonletters, either explicitly (Experiments 1-3) or implicitly (Experiment 4), a negative congruence effect was obtained for letters, contrasting with a regular, positive congruence effect for nonletters. When no distinction was to be made, letters and nonletters invariably showed a positive congruence effect (Experiments 5 and 6). In particular, between Experiments 1-4 and Experiments 5 and 6, the occurrence of negative or positive congruence effects for the same stimuli depended on the task. Feature interaction, target selection, and response competition explanations were tested against a feature integration approach. The results are explained in terms of different feature integration strategies for letters and nonletters.
\end{abstract}

Intrinsic stimulus characteristics alone fail to determine what is easy or hard to perceive; this depends on the task as well. It is easy, for instance, to perceive the geometrical structure in Figure 1A due to its saliency, but this very saliency makes it difficult to identify the letter $E$ in the figure. This elementary observation may be relevant in a number of situations in which fast and correct reactions are required. Traffic signs, as well as warning displays in power plant control rooms or cockpits, put emphasis on symbols by surrounding them with attention-grabbing frames. Yet the effect may be opposite from what is intended. Consider Figure 1B, for instance. We see a sign, composed of a letter $A$ surrounded by a similarly shaped triangular frame. The geometrical structure of the $A$ is emphasized, and its perception may be facilitated, but the perception of the $A$ as a letter seems to be obscured by the frame.

Parts of this research were aided by University Grant 22231608 from Barmer Health Insurance, BeriSoft Corperation, IAC, and others to T. L. The authors thank J. Wuest, K. Rupert, S. Jenke, S. Schlademann, W. Löhrmann, K. Sobieraska, S. Rötger, P. Rusiak, the experimental practical course class of 2003 (University of Leipzig), and D. Barton (University of Sunderland) for technical support and Albrecht Inhoff, Daphne Bavelier, and an anonymous reviewer for useful comments on earlier versions of the article. Correspondence concerning this article should be addressed to C. van Leeuwen, Laboratory for Perceptual Dynamics, RIKEN Brain Science Institute, 2-1 Hirosawa, Wako-shi, Saitama, Japan (e-mail: ceesvl@brain.riken.go.jp).

- This article was accepted by the previous editorial team, headed by Neil Macmillan
It may seem as if the experimental literature has yet to discover the task dependency of irrelevant surrounding or flanking information in perception. Flanking effects, especially in peripheral vision when the distractor information is very close, are attributed to insufficient resolution due to receptor spacing or retino-cortical transmission pooling. Disturbances still occur in peripheral vision when the separation is increased (Bouma, 1970; Hagenaar \& van der Heijden, 1986; Miller, 1991; Toet \& Levi, 1992). They also persist with increasing separation in parafoveal and foveal vision, although these effects are more restricted for central than for peripheral vision (Leat, Li, \& Epp, 1999). Because these spatial tuning functions are similar to those of masking (Chung, Levi, \& Legge, 2001), such effects have generally been attributed to early visual processing and have become known as lateral masking.

Historically, the most influential account for the lateralmasking phenomenon has assumed an interaction of flanking items at the level of local features (Estes, 1972). Local feature interaction may lead to negative congruence effects; it will be more difficult to report a target if it is surrounded by nontargets of similar shape than if it is surrounded by ones of different shape. In accordance with this view, the lateral-masking effect is larger when the flankers are similar to the targets (Estes, 1982). In the extreme, this is observed in the repeated-letter inferiority effect (Bjork \& Murray, 1977; Egeth \& Santee, 1981), where it is more difficult to report the leftmost $A$ in $A A$ than in $A E$ conditions. The feature interaction theory leaves little room for task-specific effects. Note, however, that the re- 


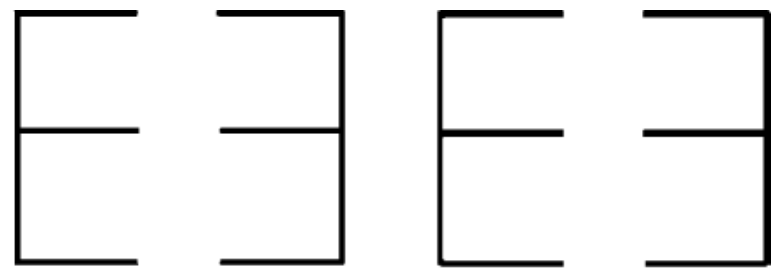

A

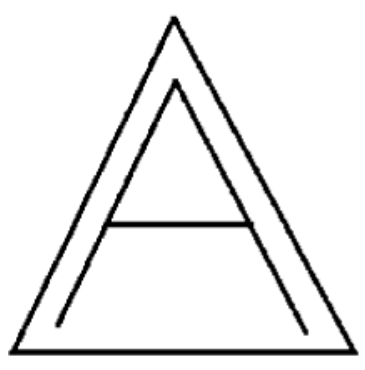

B

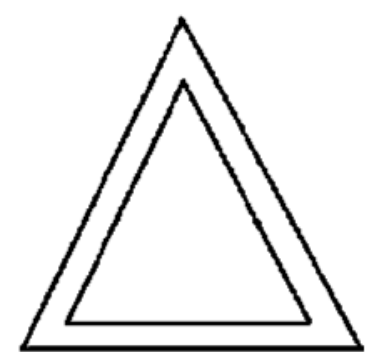

C
Figure 1. (A) The recognition of the " $E$ " is hampered by the symmetry and repetition, although these regularities normally contribute to overall figure goodness and simplicity. (B) Reading of the " $A$ " seems hampered by the surrounding frame. (C) Perception of the triangle appears unhampered by the surrounding frame.

sults of even these earliest studies cannot be understood fully on the basis of feature interaction alone. For instance, in Estes (1982), the effect of target-flanker similarity was minimal at an intermediate degree of similarity, a result Estes ascribed to the mediation of higher order processes. These processes are likely to involve task-specific factors.

In particular, we may consider the role of task-specific factors in attentional target selection. Distractor information competes for selection when the perceiver is allocating attention to the target. This effect, too, will be stronger the more similar in shape the nontarget is to the target. When the stimulus is complex, the task is difficult, and distractors competing for attention may sometimes have to be suppressed while a target is selected. This provides another possible source of negative congruence effects. Accordingly, the time it takes to classify a target is longer if it is surrounded by nontargets of similar shape than if it is surrounded by ones of different shape (Bavelier, Deruelle, \& Proksch, 2000; Briand, 1994; van Leeuwen \& Bakker, 1995). These effects contrast with those usually obtained in more simple displays, where the time it takes to classify a target is shorter when congruent distractors surround it than when it is surrounded by incongruent ones. The latter, positive congruence effects have been studied extensively and are generally attributed to competition of late response-related processes (Eriksen \& Eriksen, 1974). According to the literature, these effects are characteristic of simple stimuli, because when the task is easy (Lavie, 1995), attention recruited for feature integration (Treisman \& Gelade, 1980) spills over to irrelevant stimulus attributes. When these call for a response opposite to that of the target, response competition will result.
In sum, the effects of irrelevant surrounding information are commonly explained as a combination of early interference between features, early target selection, and late response competition (Rueckl, Suzuki, \& Yeh, 1991; Sanders \& Lamers, 2002). The first two mechanisms are associated with negative and the third with positive congruence effects. In accordance with this view, recent neurophysiological evidence has shown increased posterior, as well as frontal, cortical activity corresponding with incongruent information. The posterior activity may relate to activation of nontarget information, whereas the frontal activity may be related to response inhibition processes (Hazeltine, Poldrack, \& Gabrieli, 2000).

Task specificity plays a role in early attentional selection processes, but according to the literature, this is entirely a product of stimulus complexity. This implies that when different tasks give opposite results for same or similar stimuli, this should come from the late, but not from the early, process components.

To see the implications of this classical view, compare Figures 1B and 1C. Both inner shapes are similar to each other and are surrounded by a congruent outer frame. Lateral-masking explanations would predict a negative congruence effect for the perception of both the letter in Figure 1B and the shape in Figure 1C. As for attentional explanations, because these patterns are simple ones, a positive congruence effect would be predicted for both.

We believe, however, that despite the similarity between the targets in Figures 1B and 1C, it cannot be ignored that they belong to different contexts. The task of encoding graphical symbols as letters or words has been practiced so thoroughly that we may have acquired distinct perceptual strategies for it (Deacon, 2000; Lachmann, 2002; Zegarra-Moran \& Geiger, 1993). The type of congruence effects observed may depend on these strategies.

A prediction that accommodates the role of different strategies could be made on account of our understanding of congruence effects in terms of early feature integration (van Leeuwen \& Bakker, 1995). This approach enables strategic control over the early feature integration processes. Feature integration in early visual perception (Ross, Grossberg, \& Mingolla, 2000) plays an important role in visual target selection processes (Duncan, 1984, 1985; Duncan \& Humphreys, 1989; Wolfe \& Cave, 1999; Wolfe, Cave, \& Franzel, 1989). These processes are sensitive to relations between features. One particular class of early grouping, for instance, requires proximity and collinearity between features (Field, Hayes, \& Hess, 1993; Kovacs \& Julesz, 1993; Polat \& Sagi, 1993). Other feature integration mechanisms play a role in the early detection of complex properties, such as closure (Kovacs \& Julesz, 1993), bilateral symmetry (Julesz, 1966), or occlusion (Kanizsa, 1985). Closure (Kimchi, 1994), symmetry (Brooks \& van der Zwan, 2002; Davis, Shikano, Peterson, \& Keyes, 2003), and occlusion (Rensink \& Enns, 1995) are all known to influence target selection.

The effect of such powerful early feature integration mechanisms on subsequent target selection has led to the assumption that these early processes are automatic and, 
therefore, independent of task or strategy. Yet as has been demonstrated repeatedly (Freeman, Driver, Sagi, \& Zhaoping, 2003; Hogeboom \& van Leeuwen, 1997; Stins \& van Leeuwen, 1993; van Leeuwen \& Bakker, 1995; van Leeuwen \& van de Hof, 1991), these processes do depend on strategy. A specific theory of these top-down influences on early visual perception has been proposed in van Leeuwen and Bakker, and a computational model has been provided in van Leeuwen, Steyvers, and Nooter (1997). According to the theory, early feature binding is the consequence of the rapid synchronization between chaotic activity in the local circuits that code perceptual features (Nakatani, Khalilov, Gong, \& van Leeuwen, 2003). Because the synchronization is intrinsically unstable (Gong, Nikolaev, \& van Leeuwen, 2003) it can be sustained only for a short amount of time, posing intrinsic limitations on visual persistence. The limited time between successive synchronization and desynchronization periods poses a restriction on the scope of the early feature integration processes (coherence interval). The length of this interval shows intrinsic variability. Nevertheless, in the theory, the modal time of this interval is determined by one particular control variable. The crucial assumption is that this variable represents the single source of strategic influence on the early feature integration process. Appropriate settings of this variable determine whether feature integration is facilitated or is suppressed wholesale. When suppression occurs, features are processed in isolation. This may depend on overall individual differences, such as preference for an analytic or holistic processing style, as well as on what strategy is optimal for the given material in combination with the task.

For nonletters, there is ample evidence that these will preferably be encoded according to their symmetry properties (e.g., Garner \& Clement, 1963). Congruent surroundings enhance these properties and, thus, facilitate the preferred encoding and subsequent processes. This will lead to a positive congruence effect for nonletters in situations such as shown in Figure 1C.

For nonletter shapes, the effects of feature integration on congruence effects are clearly in evidence. The decisive factor in the size of the flanker congruence effect is not distance per se, but whether the target and the distractor are perceptually grouped (Fox, 1998). Grouping leads to the preattentive definition of objects, of which the features are processed in parallel (Banks, Bodinger, \& Illige, 1974; Banks \& Prinzmetal, 1976; Duncan, 1984). Positive congruence effects are stronger when the target and the distractor are located on the same perceptual object (Kramer \& Jacobson, 1991). Early object representations could be considered to act as modulators of (target or response) selection effects - presumably, because of automatic attention capture by objects (Ghirardelli \& Egeth, 1998).

The predominance of positive congruence effects in nonletter shapes is no evidence against its task-specific character. In Bavelier et al. (2000) and van Leeuwen and Bakker (1995), negative congruence effects were obtained for shapes. The complexity of the stimulus patterns used in these experiments appears to be an important factor for the occurrence of negative congruence effects. In a search task, increasing the complexity of the stimulus resulted in the suppression of feature integration processes (Hogeboom $\&$ van Leeuwen, 1997). The suppression facilitated a strategy in which the object could be scanned serially in a piecemeal fashion but also led to failure to perceive the global symmetry of the patterns (Hogeboom \& van Leeuwen, 1997).

Stimulus properties such as complexity are not the only possible source of differences in strategy. The difference between Figures 1B and 1C could be understood on the basis of the assumption of special preferred feature integration strategy for letters, as compared with nonletter shapes. Whereas we generally prefer to integrate figural information into a good gestalt, perception of letters, words, sentences, numbers, and punctuation marks benefit from integration at a more abstract level of encoding. The processing of letters (or words) requires specific rules for interpreting them as symbols, instead of as geometric configurations (Deacon, 2000; Friederici \& Lachmann, 2002; Lachmann, 2002; Lachmann \& Geyer, 2003). This implies that, at an early level, letters (contrary to shapes) are preferably perceived in isolation from the geometrical characteristics of flankers (Rouder \& King, 2003). This may involve the suppression of the feature integration process.

The problem with perceiving the Es in Figure 1A appears to be a difficulty of extracting an embedded element from the figure, because of global properties such as symmetry. The same may pertain to the situation in Figure 1B, where the $A$ is hard to read. We may, therefore, assume that the preferred strategy for letter perception involves the suppression of the flanking context information. This information will be harder to suppress if its autonomous integration is facilitated by a similarity in shape. The resulting competition between shape and letter strategies (Joseph, Gathers, \& Piper, 2003) will make it more difficult to process the letter in a congruent than in an incongruent surrounding context.

Comparing letters with nonletters may cast a new light on the influence of strategic processes. In a recent series of experiments, pseudoletters and rotated letters produced more lateral masking than did letters (Huckauf, Heller, \& Nazir, 1999). This result was attributed to the absence of higher order representations in the pseudo- and rotated letters that reduce the flanking effect for letters. The effect, therefore, illustrates the influence of higher order processes on lateral masking (Di Lollo, Enns, \& Rensink, 2000). Early mediation could explain, for instance, the fact that repeated-letter inferiority is still in evidence for Aa conditions (Egeth \& Santee, 1981). Another interesting aspect of Huckauf et al.'s (1999) results is that the effects were largest at intermediate distances. There are symbolic aspects to the distance effect (Mewhort, Marchetti, \& Campbell, 1982), and these could play a role here, too-for instance, because the intermediate sizes represent default object sizes. Early mediation by higher 
order processes could also be of significance for situations such as those in Figure 1.

If there are indeed such strong differences in feature integration strategies between letters and nonletters, why has this not been observed so far in flanker congruence effects? The answer, in our view, is to be found in the strategic character of early feature integration processes. Strategic influences are well documented for, again, figures. It has been shown, for instance, that prior information about target location restricts the scope of the flanking effect (Paquet \& Lortie, 1990; van der Lubbe \& Keuss, 2001). The effects of strategy on the flanker effect modulation are similar to those Besner (2001) demonstrated in the related Stroop task (Stroop, 1935). Effect reversals can even be obtained, depending on the availability of a strategy; in Cepeda and Kramer (1999), an advantage was obtained for congruent items lying on different, instead of the same, objects. This may have been the case because the task was solved using a mental rotation strategy, which identified both objects through a mental transformation.

The failure to observe effects of different organization strategies for figures and letters is probably due to the task and context sensitivity of these strategies. Many (in fact, most) flanker experiments have been done with letters. Some have compared effects for letters and nonletter shapes. But to the best of our knowledge, none of these experiments has required participants to actually distinguish letters and shapes. Lacking such a differentiation, it is possible, and mostly easier in the context of an experiment, to perform a task with a uniform shapes strategy, requiring no suppression of the spontaneous perceptual integration processes. In other words, in order to observe the predicted effects, we will have to require our participants to distinguish letters and shapes.

This assumption automatically implies that if the task does not require such a distinction, we will observe for the same letter stimuli a different congruence effect from that observed when it is required. In the former case, we would expect a positive congruence effect also for these letter stimuli, contrasting with a negative effect in the latter case.

These predictions are made in accordance with a feature integration explanation of congruence effects. The aim of the present article is to investigate the congruence effects for letters and shapes in situations such as those shown in Figure 1. This enables a test of feature integration predictions against those that ascribe the effect to lateral masking or target selection without distinguishing letter and nonletter perception strategies. Our prediction is that negative effects will occur for letters, contingent on the use of the letter perception strategy. To enable this strategy, the task must require participants to distinguish letters and nonletters. Otherwise, we may expect that the same nonletter strategy will be used (as, generally, in the flanker task), leading to positive congruence effects for both letters and nonletters - and thus, to task dependency for the same letter stimuli.

The prediction that negative congruence effects will be obtained in simple displays for letters, but only when partic- ipants are required to distinguish letters from nonletters, was tested in six experiments. Experiment 1 tested the basic effect for letters versus shapes. Experiment 2 replicated the effect for nonletters that were maximally similar to letters. We performed control experiments to test the possibility that response-related processes were responsible for the effects obtained. Experiments 3 and 4 tested this explanation. Experiments 5 and 6 tested the possibility that the requirement that the participants distinguish letters and shapes is a condition for the negative congruence effect to occur. A comparison of the congruence effects for letters in the last two experiments with those in the earlier ones will establish whether there is a difference in strategy for the same set of stimuli.

\section{EXPERIMENT 1}

A task was chosen that required participants to distinguish letters from shapes. A two-alternative letters versus shapes classification task was used for this purpose. We used foveal presentation, so as to minimize any inhibitory effects of the surrounding shape caused by lateral masking. There were clear segmentation cues and simple images, so as to minimize target selection problems (Figure 2). Under these conditions, a positive congruence effect
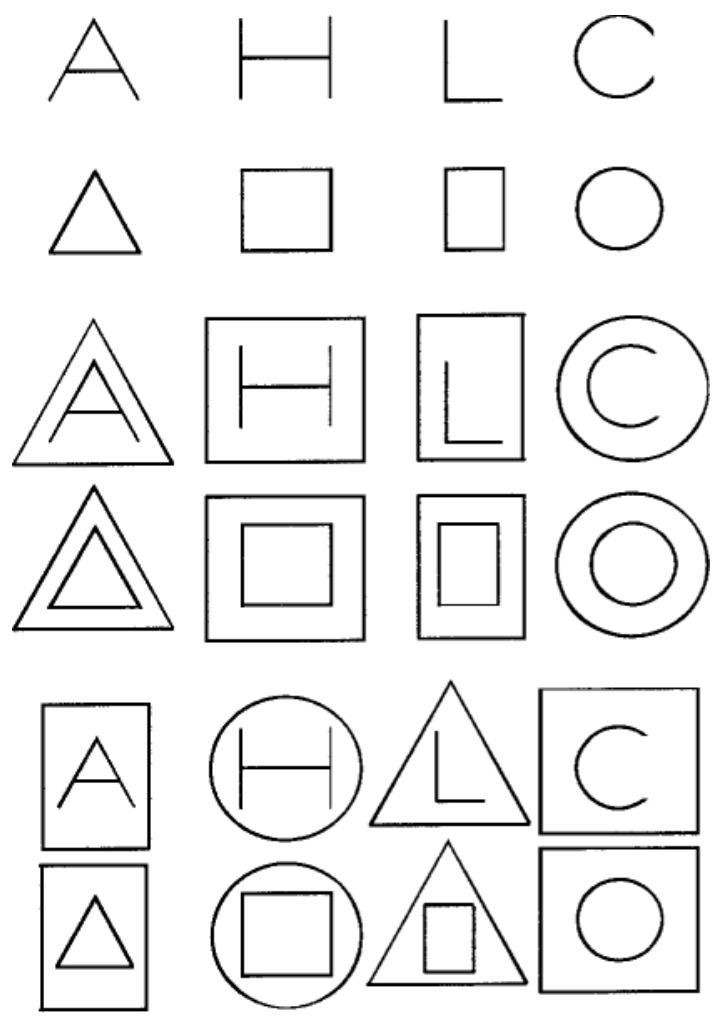

Figure 2. Example stimuli from Experiment 1. Top row, isolated letters; second row, isolated shapes; third row, congruent letters; fourth row, congruent shapes; fifth row, incongruent letters; bottom row, incongruent shapes. 
would normally be expected (see Bavelier et al., 2000). In our present experiment, we predicted this effect when shapes were surrounded by shapes. But for letters surrounded by shapes, the opposite was predicted, as a result of a letter perception strategy.

\section{Method}

Participants. The participants were 29 students ( 22 female) of the University of Leipzig, aged between 21 and 29 years of age, who either were paid or received course credit for their participation. All the participants had normal or corrected-to-normal vision.

Materials. Target stimuli were the four capital letters (A, H, L, and $\mathrm{C}$ ) and four geometrical objects that correspond to the outline envelopes of the letters (a triangle, a square, a rectangle, and a circle, respectively). Targets were shown in isolation or surrounded by one of four nontarget geometrical shapes. These were slightly enlarged versions of the triangle, square, rectangle, and circle targets (Figure 2). The geometrical targets were similar in shape to the corresponding set of letters. Targets and nontargets were combined in such a manner that the surrounding shapes could be congruent or incongruent with respect to the target. In total, there were six sets of stimuli: isolated letters, isolated geometrical objects, letters within congruent surrounding shapes, letters within incongruent surrounding shapes, geometrical shapes within congruent surrounding shapes, and geometrical shapes within incongruent surrounding shapes. Each set contained four stimuli, resulting in a total of 24 unique displays.

The stimuli were scaled to an imaginary $50 \times 50 \mathrm{~mm}$ matrix and the surrounding shapes to an imaginary $80 \times 80 \mathrm{~mm}$ matrix. All the stimuli were presented in black $\left(0.46 \mathrm{~cd} / \mathrm{m}^{2}\right)$ on a CRT computer monitor screen set to white $\left(28 \mathrm{~cd} / \mathrm{m}^{2}\right)$. They were presented at about a $50-\mathrm{cm}$ distance, resulting in a visual angle of about $3^{\circ}$ without and $4.5^{\circ}$ with a surrounding. The participants were seated comfortably in a chair with a headrest, without fixation of their heads. The experiment took place in a dimly lit room without windows.

Procedure. The instructions were given in written form on the monitor screen. The participants were instructed to classify as quickly and as accurately as possible whether an item shown was a shape (for the geometrical targets) or a letter (for the capital letter targets) and to ignore the surrounding shape, whenever one occurred, as irrelevant. The response was given by pressing one of two response keys, which were connected with the computer by the parallel port. Response key allocation was counterbalanced across participants. Prior to the experiment, the participants had conducted a practice session of 30 trials, using the same procedure as that in the experiment, which was as follows. First, a fixation cross $(10 \times 10 \mathrm{~mm})$ was presented for $300 \mathrm{msec}$ on the center of the screen at the position that marked where the target stimulus would follow. After that, the screen remained clear for $300 \mathrm{msec}$, followed by the target stimulus, which was shown for $150 \mathrm{msec}$ and then disappeared. After the response, the screen remained clear for $200 \mathrm{msec}$ before the next fixation cross appeared. No feedback was given. During one block, the 24 stimuli were shown three times each in a fully random order.
Each participant performed five blocks, with a short break between each (about $30 \mathrm{sec}$ ), which resulted in a total session of 360 decisions per participant, lasting about $20 \mathrm{~min}$.

\section{Results}

The data for a total of 10,440 responses were analyzed for reaction times (RTs) and error rates. In order to remove outliers, only those responses were entered into computation of which the RT was not higher than $M+5 S D$ | $145<\mathrm{RT}<3,000$. According to this criterion, $0.6 \%$ of the cases were excluded from further analyses. These 59 cases were equally distributed over the experimental conditions and individuals. Only correct responses were used for the RT analyses.

Mean RTs for correct responses and error rates for the conditions are displayed in Table 1 . The overall mean RT was $463.2 \mathrm{msec}(S D=95.7 \mathrm{msec})$ and ranged from $385 \mathrm{msec}(S D=67 \mathrm{msec})$ to $548 \mathrm{msec}(S D=107 \mathrm{msec})$ for the individual participants. The mean error rate was $4.3 \%$ and ranged from $1.4 \%$ to $13.1 \%$ for individual participants. More than half of them $(n=16)$ made between $2 \%$ and $4 \%$ errors, and only 4 made more than $10 \%$ errors. Individual participants' mean error rates and RTs were negatively correlated $\left(R^{2}=.31 ; p<.01\right)$; faster participants made more errors. Because of possible speedaccuracy tradeoff, both RTs and error rates were analyzed.

Analyses of variance (ANOVAs) for repeated measurements and post hoc pairwise comparisons were performed on RTs and error rates. In a first ANOVA, all the experimental factors and levels were included. This 2 (material: letter vs. shape) $\times 3$ (context: isolated, congruent surrounded, or incongruent surrounded) analysis revealed significant main effects on RTs for material $[F(1,28)=$ $26.4, p<.01]$ and context $[F(2,56)=12.4, p<.01]$ and a significant interaction of these factors $[F(2,56)=12.1$, $p<.01$; see Figure 3]. The analysis of error rates revealed similar results; material $[F(1,28)=101.4, p<.01]$ and context $[F(2,56)=158.7, p<.01]$, as well as their interaction $[F(2,56)=125, p<.01]$, reached significance.

These effects were investigated more specifically in post hoc designs. A $2 \times 2$ analysis on RTs, with material, (letter vs. shape) and surroundings (isolated vs. surrounded) as factors, showed that the task was performed more quickly without $(458 \mathrm{msec})$ than with $(464 \mathrm{msec})$ surroundings $[F(1,28)=28.5, p<.01]$ and more quickly for letters $(454 \mathrm{msec})$ than for shapes $[473 \mathrm{msec} ; F(1,28)=34.6$, $p<.01]$. No interaction was found $[F(1,28)=0.4, p>$

Table 1

Condition Means in Experiment 1

\begin{tabular}{lllrrr}
\hline \multirow{2}{*}{ Targets } & & & \multicolumn{2}{c}{ Reaction Time $(\mathrm{msec})$} & \\
Letters & Context & Congruence & $M$ & $S D$ & Error Rate (\%) \\
& Isolated & & 449.9 & 94.3 & 2.4 \\
& Surrounded & Congruent & 463.6 & 102.1 & 3.5 \\
\multirow{3}{*}{ Shapes } & & Incongruent & 450.1 & 90.3 & 2.9 \\
& Isolated & & 466.4 & 95.8 & 2.4 \\
& Surrounded & Congruent & 471.6 & 94.1 & 3.1 \\
& & Incongruent & 480.0 & 93.3 & 15.8 \\
\hline
\end{tabular}




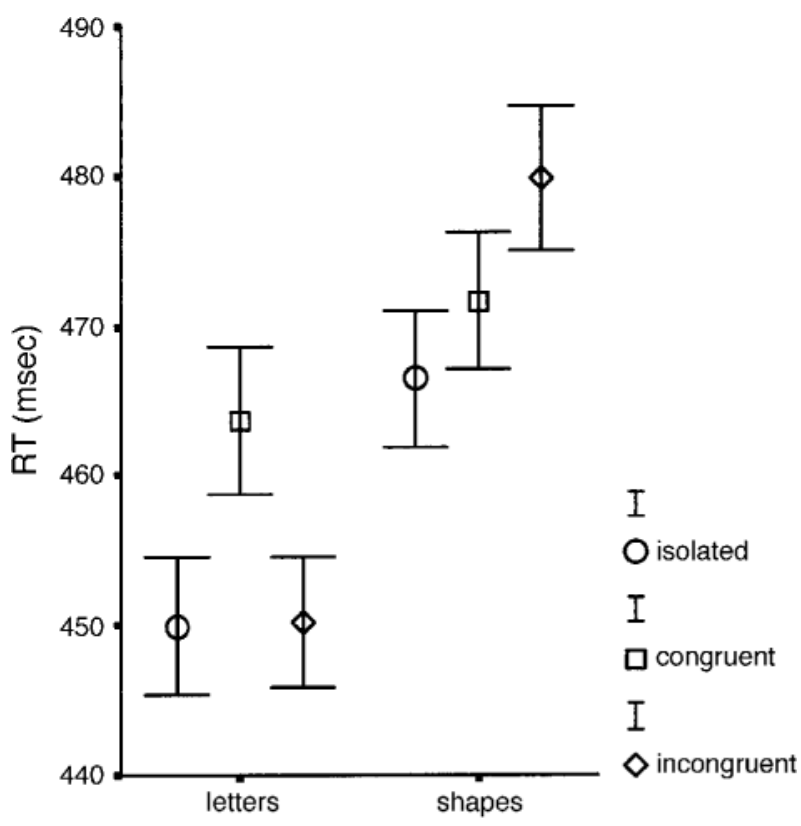

Figure 3. Average reaction times (RTs) and SDs from Experiment 1.

.1]. Similar results were obtained from the error rate analysis. Fewer errors were made for isolated items $(2.4 \%)$ than for surrounded ones $[6.3 \% ; F(1,28)=97.2, p<.01]$ and for letters $(2.9 \%)$ than for shapes $[7.1 \% ; F(1,28)=$ $53.7, p<.01]$. These factors, however, interacted significantly $[F(1,28)=72.3, p<.01]$. Post hoc pairwise comparisons confirmed that this was because of a very high error rate for incongruent surrounded shapes.

The following analyses were carried out for isolated and surrounded targets, separately. For isolated items, letters were recognized more quickly $(450 \mathrm{msec})$ than were shapes [466 msec; $F(1,28)=21.1, p<.01]$. The same analyses on error rates revealed no difference between letters and shapes presented in isolation $[2.4 \% ; F(1,28)=$ $0.02, p>.1]$.

For surrounded targets, a $2 \times 2$ ANOVA on the material and congruence factors was performed; the main effect was significant for material $[F(1,28)=19.1, p<.01]$, but not for congruence $[F(1,28)=1.3, p>.1]$. The interaction was significant $[F(1,28)=30.4, p<.01]$. Post hoc pairwise comparisons revealed that shapes were recognized more quickly in a congruent $(472 \mathrm{msec})$ than in an incongruent $(480 \mathrm{msec})$ surrounding $[F(1,28)=9$, $p<.05]$. In contrast, letters were recognized more quickly in an incongruent $(450 \mathrm{msec})$ than in a congruent $(464 \mathrm{msec})$ surrounding $[F(1,28)=19, p<.01]$.

For error rates, main effects occurred for both material $[F(1,28)=172, p<.01]$ and congruence $[F(1,28)=237$, $p<.01]$. The interaction was also significant $[F(1,28)=$ $161, p<.01]$. Shapes were recognized more accurately with congruent $(3.1 \%)$ than with incongruent $(15.8 \%)$ surroundings. For letters, the effect was opposite ( $3.5 \%$ vs. $2.9 \%$ ), albeit not significantly, from a post hoc pairwise comparison.

\section{Discussion}

The results show a positive congruence effect for shapes. Shapes in a congruent surrounding are processed more quickly and more accurately than those in an incongruent surrounding. This effect is very similar to what generally is obtained for letters flanked by letters (Eriksen \& Eriksen, 1974) and for shapes flanked by shapes (Pomerantz \& Pristach, 1989). Effects of positive flanker congruence are usually interpreted in terms of interference at the response selection stage, although perceptual explanations have been given, for instance, in terms of target selection (Bavelier et al., 2000) or stimulus integration (van Leeuwen \& Bakker, 1995).

The positive congruence effects for shapes contrast strongly with the negative congruence effect obtained for letters surrounded by shapes. That letters are classified more quickly with incongruent than with congruent surrounding shapes constitutes the main finding of the first experiment. Its explanation, according to the feature integration approach, is based on the preference to encode letters in abstraction from their geometrical configuration. We will consider four alternative explanations. The first is that the difference is due to an asymmetry between the shape and the letter conditions. Shape targets are identical to their surrounding shapes; letters are merely similar. Although it is hard to see how this observation could lead to the explanation of a negative congruence effect for letters, the imbalance in the stimuli cannot be denied. We dealt with this problem in Experiment 2.

Another imbalance in the stimuli is that the surroundings are always shapes. It would be preferable, in principle, to have both shapes and letters as surroundings, enabling orthogonal variation of targets and surroundings with letters and nonletters. However, for the aim of testing the target selection approach, patterns are required that are simple and of which the surroundings enhance the symmetry of the targets. This is hard to realize with letters. So, instead of orthogonal variation, a different strategy was taken for the balancing conditions in the next two experiments, leaving orthogonal variation for later studies.

A second attempt to explain the present result is in terms of lateral masking. However, the stimuli are foveated, which minimizes the effect of lateral masking. Moreover, the preferred surrounded conditions (congruent for shapes, incongruent for letters) invariantly score as good, in both RTs and error rates, as the isolated letters. In other words, for these patterns, there is no flanking masking, making it unlikely that it occurs for the unpreferred ones.

A third explanation assumes target selection problems along the lines discussed in Bavelier et al. (2000). However, the stimuli are very simple, and the targets are nowhere connected to the surroundings, making such an explanation unlikely. Moreover, targets in their preferred surroundings (congruent for shapes, incongruent for letters) are processed equally quickly as isolated targets. This observation excludes target selection problems as an explanation for the negative congruence effect observed for letters in this experiment. 


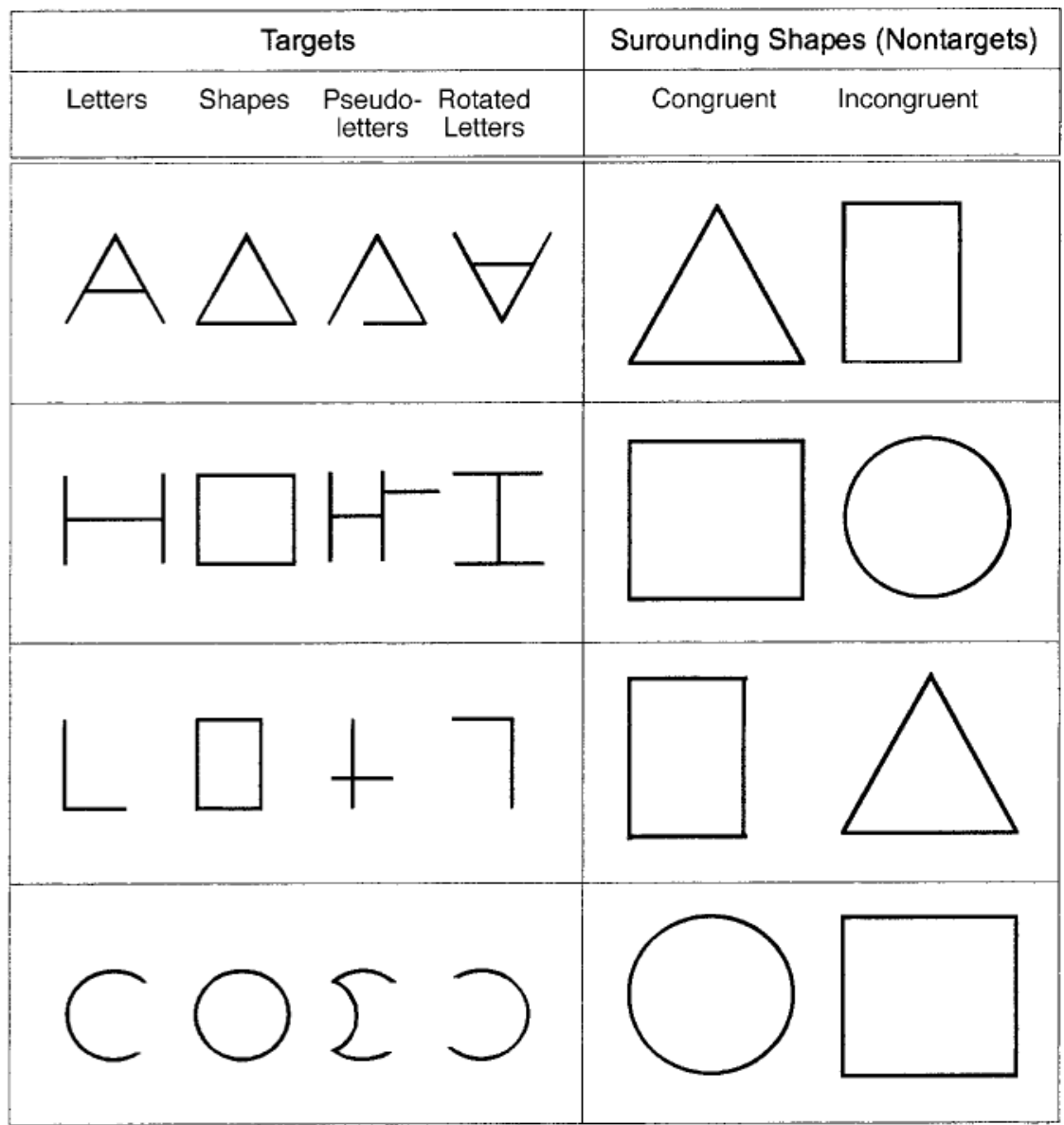

Figure 4. Stimuli used in Experiments 2-6.

A fourth possible alternative explanation assumes that the effect is based on response competition. Response competition could explain negative congruence effects as follows. It is acknowledged that in classifying letters as letters, it may be harder to ignore the surroundings if they are similar in shape to the target letters. But rather than interfering with the perceptual feature integration strategy, this will result in an enhanced tendency to respond with "shape." This explanation has great intuitive appeal and deserves to be taken very seriously. The letters-versus-shapes classification task was chosen in order to require the participants to distinguish between letters and shapes. The imbalance in response categories that results makes this a possible alternative explanation. Experiments 3 and 4 were devoted to testing this hypothesis.

\section{EXPERIMENT 2}

Before we dealt with the response competition hypothesis, we wished to extend the results and control for an imbalance in the previous experiment. Whereas the target letters were chosen to be similar to the surrounding shapes, the target shapes were identical to the surrounding shapes, differing only in size. Shapes that were more equivalent to the letters used in the degree of their similarity to the surrounding shapes were needed, in order to perform the subsequent crucial experiments. In the present experiment, shapes were used that were more similar to letters than to the surrounding shapes. Pseudoletters and rotated letters were used as shapes. The pseudoletters chosen shared local features with the letters; the rotated letters shared their local and global features in a different orientation. We assumed that pseudoletters and rotated letters were encoded with a shapes strategy. For the latter, this implied that the letters had an orientation-specific encoding. The case for this is still open (Bigsby, 1988; Eley, 1982; Greenberg \& Krueger, 1983) but could be verified in the context of this experiment and the next one. If letter encoding is orientation specific, the same degree of positive congruence effects will be expected for rotated letters as for pseudoletters and for geometric shapes.

\section{Method}

Participants. The participants were 31 students ( 21 female) at the University of Leipzig, between 21 and 29 years of age, who either were paid or received course credit for their participation. All the participants had normal or corrected-to-normal vision.

Materials and Procedure. As in Experiment 1, the task was letters-versus-shapes classification. The same four capital letters (A, 
Table 2

Condition Means in Experiment 2

\begin{tabular}{|c|c|c|c|c|c|}
\hline \multirow[b]{2}{*}{ Targets } & \multirow[b]{2}{*}{ Context } & \multirow[b]{2}{*}{ Congruence } & \multicolumn{2}{|c|}{ Reaction Time (msec) } & \multirow[b]{2}{*}{ Error Rate (\%) } \\
\hline & & & $M$ & $S D$ & \\
\hline \multirow[t]{3}{*}{ Letters } & Isolated & & 438.1 & 134.6 & 6.1 \\
\hline & Surrounded & Congruent & 445.1 & 124.2 & 4.3 \\
\hline & & Incongruent & 439.8 & 113.5 & 4.4 \\
\hline \multirow[t]{3}{*}{ Pseudoletters } & Isolated & & 465.5 & 137.8 & 3.7 \\
\hline & Surrounded & Congruent & 456.5 & 108.1 & 4.4 \\
\hline & & Incongruent & 467.9 & 115.0 & 3.3 \\
\hline \multirow[t]{3}{*}{ Rotated letters } & Isolated & & 472.7 & 128.6 & 9.5 \\
\hline & Surrounded & Congruent & 471.6 & 126.7 & 9.3 \\
\hline & & Incongruent & 482.0 & 146.1 & 8.5 \\
\hline
\end{tabular}

$\mathrm{H}, \mathrm{L}$, and C) were used as letters. In the present experiment, however, modified letters were classified as shapes. Modified letters for half of the participants $(n=15)$ were pseudoletters that were obtained by deforming or displacing component features in each of the letters (see Figure 4). The modified letters for the rest of the participants were rotated versions of the original letters (the degree of rotation depending on the symmetry axes of the letters; see Figure 4). Thus, the task differed from classical letters versus shapes classification in that rotated letters were classified as shapes. As in the first experiment, the targets were shown either isolated or with a surrounding (nontarget) shape, which, as in the previous experiment, was a triangle, a square, a rectangle, or a circle (see Figure 4). Surrounding shapes could be congruent or incongruent with respect to a letter or shape. As in Experiment 1, each participant received six sets of stimuli: isolated letters, isolated modified letters, letters within congruent or incongruent surrounding shapes, and modified letters within congruent or incongruent surrounding shapes. Each set contained four elements, resulting in a total of 24 unique stimuli for each participant, which were shown three times each in one session. Again, each participant performed in five sessions. All other parameters, as well as the procedure, were the same as those in Experiment 1.

\section{Results}

From the total of 11,160 responses, RTs and error rates were subjected to the same exclusion criteria as those in Experiment 1 . The excluded trials $(0.9 \%)$ were uniformly distributed across conditions. For RT analyses, only correct responses within this range were included.

Mean RTs and error rates are displayed in Table 2. The overall mean RT was $455 \mathrm{msec}(S D=126.9 \mathrm{msec})$ and ranged from $384 \mathrm{msec}(S D=56 \mathrm{msec})$ to $560 \mathrm{msec}(S D=$ $174 \mathrm{msec}$ ) for the individual participants. The mean error rate was $5.7 \%$ and ranged from $0.3 \%$ to $16.1 \%$ for the individual participants. Most of them $(n=21)$ made fewer than 5\% errors. Individual mean error rates and mean RTs were weakly negatively correlated $\left(R^{2}=.22, p=.047\right)$; faster participants made more errors. Because of this, both RTs and error rates were analyzed.

In the first analyses the data from the rotated and the pseudoletter conditions were pooled, on the basis of the assumption that both pseudoletters and rotated letters are preferably perceived as shapes to the same extent. In this manner, the same analyses as those in Experiment 1 could be performed on the data from approximately the same number of participants.

A first $2 \times 3$ ANOVA was performed, including all factors and levels. The main effect for context (isolated, con- gruent surround, or incongruent surround) was not significant $[F(2,60)=0.8, p>.05]$. The main effect for material [letter vs. shape; $F(1,30)=50.7, p<.01$ ] and the interaction between the factors $[F(2,60)=7.3, p<.01]$ were significant. For error rate analyses, only the main effect for context reached significance $[F(2,60)=5.7, p<.05]$.

A $2 \times 2$ analysis with the material (letters vs. shapes) and surroundings (isolated vs. surrounded) as factors showed faster responses for letters $(441 \mathrm{msec})$ than for rotated or pseudoletters [469 msec; $F(1,30)=47, p<.01$ ] Surroundings had no significant effect; a response to isolated targets took $456 \mathrm{msec}$, whereas surrounded ones needed $454 \mathrm{msec}[F(1,30)=1, p>.1]$. No interaction between material and surroundings was found $[F(1,30)=$ $0.2, p>.1]$. The corresponding analysis for error rates revealed no difference between letters $(5 \%)$ and rotated or pseudoletters $[6.5 \% ; F(1,30)=1, p>.1]$. There was a small but statistically significant effect of surroundings on error rate; surrounded targets were responded to more accurately $(5.4 \%)$ than isolated ones $[6.4 \% ; F(1,30)=6.4$, $p<.05]$. No interaction was found $[F(1,30)=2.5, p>.05]$.

Analyses comparable to those in Experiment 1 were carried out separately for isolated and surrounded targets. When isolated, letters were recognized more quickly $(438 \mathrm{msec})$ than rotated or pseudoletters [469 $\mathrm{msec}$; $F(1,30)=30, p<.01]$. Error rates for isolated targets failed to reach significance for letters $(6.1 \%)$ versus rotated or pseudoletters $[6.7 \% ; F(1,30)=0.1, p>.1]$.

For surrounded targets, a $2 \times 2$ ANOVA with material (letters vs. shapes) and congruence (congruent vs. incongruent surround) as factors resulted in a significant main effect for material $[F(1,30)=48.2, p<.01]$, but not for congruence $[F(1,30)=0.5, p>.1]$. The interaction proved to be significant $[F(1,30)=18.5, p<.01]$. Post hoc pairwise comparisons revealed that, for the shapes material (rotated letters or pseudoletters), responses were faster with congruent $(464 \mathrm{msec})$ than with incongruent $(475 \mathrm{msec})$ surroundings $[F(1,30)=22.7$, $p<.01]$. This congruence effect matches that of the shapes in Experiment 1. A negative effect of congruence was found for letters $[F(1,30)=4.2, p<.05]$, identical to that in the previous experiment.

The same analysis for error rates revealed a main effect for congruence $[F(1,30)=4.5, p<.05]$. There was no ef- 
fect for material $[F(1,30)=2.3, p>.05]$ and no interaction $[F(1,30)=0.2, p>.1]$.

To compare between rotated letters and pseudoletters, a $2 \times 2 \times 2$ ANOVA with material (letters vs. shapes) and congruence (congruent vs. incongruent surround) as within-subjects factors and modification (rotated letter vs. pseudoletter) as a between-subjects factor was performed on the surrounded target conditions. A significant main effect was found for material $[F(1,29)=48.5, p<.01]$, but not for congruence $[F(1,29)=0.5, p>.1]$ or for modification $[F(1,14)=0.3, p>.1]$. There was no interaction between congruence and modification $[F(1,29)=0.3$, $p>.1]$, between material and modification $[F(1,29)=$ $1.6, p>0.1]$, or between all of these factors $[F(1,29)=$ $0.5, p>0.1]$. The one and only interaction found was that for material and congruence $[F(1,29)=18.3, p<.01]$, indicating the same as in the previous analysis: a positive congruence effect for rotated letters and pseudoletters and a negative congruence effect for letters. From the absence of any other interactions, it can be confirmed that rotated letters and pseudoletters were responded to similarly. This implies that, in the context of the present paradigm, they were perceived as shapes with the same degree of preference. This confirmed our working hypothesis, which led to the pooling of rotated letter and pseudoletter conditions in the earlier analyses.

For error rates, a main effect for congruence was obtained $[F(1,29)=4.7, p=.04]$. A tendency for more errors with rotated letters than with pseudoletters failed to reach significance $[F(1,29)=3.7, p>.05]$. No interactions involving modification were found, either with material $[F(1,29)=2, p>.05]$ or with congruence $[F(1,29)=1.5$, $p>.05]$, nor was there a three-way interaction with these factors $[F(1,29)=0.2, p>.1]$.

Nevertheless, separate congruence $\times$ material ANOVAs were performed for the data of the 15 participants who received pseudoletters and for the 16 participants who received rotated letters. For the pseudoletters, a significant main effect was found for material $[F(1,14)=22, p<$ $.01]$, but not for congruence $[F(1,14)=0.2, p>.1]$. The interaction proved to be significant $[F(1,14)=14.1, p<$ $.01]$. Post hoc pairwise comparisons revealed that pseudoletters were recognized more quickly with congruent than with incongruent surroundings $[F(1,14)=18.1, p<.01]$. The effect of congruence on normal letters, however, failed to reach the $5 \%$ criterion and was significant only at the $10 \%$ level $[F(1,14)=3.4, p=.09]$. For error rates, the $2 \times 2$ ANOVA revealed no significant main effect for material $[F(1,14)=0.01, p>.1]$ or for congruence $[F(1,14)=4, p=.06]$ and no interaction $[F(1,14)=0$, $p>$.1].

For rotated letters, a significant main effect was found for material $[F(1,15)=28, p<.01]$, but not for congruence $[F(1,15)=0.4, p>.1]$. The interaction proved to be significant $[F(1,15)=5.8, p<.05]$. Post hoc pairwise comparisons revealed that rotated letters were recognized more quickly with congruent than with incongruent surroundings $[F(1,15)=7.3, p<.05]$. The effect of congru- ence on normal letters was not significant $[F(1,15)=1.1$, $p>.05]$. The tendency, however, was in accordance with that in the first experiment. For error rates, the $2 \times 2$ ANOVA again revealed no significant main effect for material $[F(1,15)=2.5, p>.05]$ or for congruence $[F(1,15)=$ $0.7, p>.1]$, and no interaction $[F(1,15)=0.03, p>.1]$.

\section{Discussion}

The results are consistent with those in the previous experiment; the main outcome of negative congruence effects for surrounded letters was replicated in the present experiment. Rotated letters and pseudoletters showed a positive congruence effect, similar to that for the geometrical shapes in Experiment 1, this despite the fact that they resembled the letters more than they did the surrounding shapes. The effects, therefore, cannot be attributed to imbalances in the degree of similarity between the targets and their surroundings. The positive congruence effect was equal for rotated letters and pseudoletters. This means that, in the context of the present paradigm, both were perceived as shapes with the same preference. This is in accordance with the notion that letters are encoded in an orientation-specific format.

In the rotated letters condition, however, RTs were longer and more errors were produced than in any other condition. This effect could be ascribed to response competition, occurring when rotated letters were to be identified as nonletters. This might seem to involve a paradox, for how could such a response conflict arise if rotated letters are not encoded as letters? However, the response conflict could occur if the perceptual strategy to encode these objects as shapes is rivaled by a strategy to encode them as letters. Perhaps both encodings are performed, one being predominant over the other. The resulting letter encoding of the rotated letters may be sufficient to generate the response conflict. Alternatively, the rivalry may directly generate a delay in resolving the ambiguity within the perceptual system. Either way, the extra time needed for the rotated letters constitutes evidence for the presence of rivalry between two perceptual strategies. Yet this does not affect the negative congruence effects.

\section{EXPERIMENT 3}

This experiment was the first to be performed to test the response competition hypothesis against the feature integration hypothesis. According to the former hypothesis, the negative congruence effect for letters is a product of explicitly classifying objects in a letter category. According to the perceptual feature integration hypothesis, the effect results from the interference of the surrounding shape with the letter-processing strategy. Whereas in the former hypothesis, negative congruence depends on the response category, this is defined by the latter hypothesis.

In the present experiment, rotated letters played a crucial role. The stimuli in the present experiment consisted of shapes, pseudoletters, rotated letters, and letters. Whereas shapes and pseudoletters were to be classified as shapes, 
letters and rotated letters were to be classified as letters. Note that this placed the rotated letters in the opposite category from the one in the previous experiment. Response competition was observed for the category of rotated letters in the previous experiment because they had to be classified as shapes, instead of as letters. This means that, at some stage in the process, the letter concept was evoked by these stimuli. In the present experiment, they would be classified as letters. According to the response competition explanation, the new classification for rotated letters would resolve one response conflict only to recreate another. The rotated letters would now undergo the same response conflict as upright letters. Both would now, according to this hypothesis, show a negative congruence effect, just as for upright letters.

The feature integration hypothesis predicts that rotated letters will still be perceived as shapes at the stage at which the perceptual strategy is determined. This decision rules over whether positive or negative congruence effects are obtained. According to this hypothesis, it is irrelevant to which response category the stimuli are allocated. For this reason, an unchanged positive congruence will still be expected for the rotated letters, even if they are now to be classified as letters instead of shapes.

\section{Method}

Participants. The participants were 25 students ( 21 female) at the University of Leipzig, between 20 and 31 years of age, who either were paid or received course credit for their participation. All the participants had normal or corrected-to-normal vision.

Materials and Procedure. The stimuli from both of the previous experiments were combined for presentation in the present experiment. Targets in the shape category consisted of the geometrical shapes in Experiment 1 and the pseudoletters in Experiment 2. The letters category consisted of the four capital letters in Experiment 1 (and 2), together with the rotated letters in Experiment 2. (Note that in Experiment 2, the latter were classified as shapes.) As in the previous experiments, the target was shown either isolated or with a congruent or an incongruent surrounding (nontarget) shape, which was a triangle, a square, a rectangle, or a circle. The total set of stimuli thus consisted of 4 (geometrical objects, pseudoletters, rotated letters, and letters) $\times 4$ (objects within each category) $\times 3$ (isolated vs. congruent vs. incongruent) $=48$ unique stimuli. These were repeated three times within a block of 144 trials, which were shown in random order. A total of five blocks were shown, and the participants were allowed a short break between blocks. The total duration of the experiment was approximately $25 \mathrm{~min}$.

\section{Results}

The same exclusion criteria as those in Experiment 1 were applied to the total of 18,000 responses obtained. The excluded $186(1 \%)$ responses were uniformly distributed across conditions. For RT analyses, only correct responses were included.

Mean RTs and error rates are displayed in Table 3. Note that the letters RTs, incidentally, were identical to those in the previous experiment. The overall mean RT was $456.4 \mathrm{msec}(S D=106 \mathrm{msec})$ and ranged from $374 \mathrm{msec}$ $(S D=70 \mathrm{msec})$ to $584 \mathrm{msec}(S D=131 \mathrm{msec})$ for the individual participants. The mean error rate was $6.2 \%$ and ranged from $0.7 \%$ to $14.6 \%$ for the individual participants. Only 5 participants made more than $10 \%$ errors. Individual mean error rates and mean RTs were correlated $\left(R^{2}=.3, p<.05\right)$; faster participants made more errors.

A first $3 \times 4$ ANOVA was performed including all factors and levels. The main effects for context (isolated, congruent surround, or incongruent surround) and material (letter, rotated letter, pseudoletter, or shape) were significant at the $p<.001$ level $[F(2,48)=26.2$, and $F(3,72)=$ 28.2 , respectively], and the interaction was significant $[F(6,144)=3.2]$ at $p<.05$. Letters $(438 \mathrm{msec})$ were responded to more quickly than rotated letters $(450 \mathrm{msec})$, followed by shapes ( $467 \mathrm{msec})$ and pseudoletters $(470 \mathrm{msec})$; for the latter two, there was no significant difference in RTs. For error rate analyses, only the interaction reached significance $[F(6,144)=2.5, p<.05]$.

A $4 \times 2$ analysis with material (4) and surroundings (isolated vs. surrounded) as factors showed a significant effect for material $[F(3,72)=28, p<.01]$. Surroundings was significant $[F(1,24)=33.4, p<.01]$; RTs for isolated items $(450 \mathrm{msec})$ were shorter than those for surrounded items $(460 \mathrm{msec})$. The interaction between these factors was not significant $[F(3,72)=1.45]$. The corresponding analysis for error rates revealed no significant effects.

Post hoc analyses comparable to those in Experiment 1 were carried out for surrounded targets only. For sur-

Table 3

Condition Means in Experiment 3

\begin{tabular}{|c|c|c|c|c|c|}
\hline \multirow[b]{2}{*}{ Targets } & \multirow[b]{2}{*}{ Context } & \multirow[b]{2}{*}{ Congruence } & \multicolumn{2}{|c|}{ Reaction Time (msec) } & \multirow[b]{2}{*}{ Error Rate $(\%)$} \\
\hline & & & $M$ & $S D$ & \\
\hline \multirow[t]{3}{*}{ Letters } & Isolated & & 430.9 & 107.0 & 5.3 \\
\hline & Surrounded & Congruent & 445.7 & 102.1 & 6.4 \\
\hline & & Incongruent & 439.1 & 105.6 & 5.5 \\
\hline \multirow[t]{3}{*}{ Rotated letters } & Isolated & & 441.5 & 101.4 & 8.7 \\
\hline & Surrounded & Congruent & 450.4 & 104.2 & 7.0 \\
\hline & & Incongruent & 458.3 & 108.5 & 9.3 \\
\hline \multirow[t]{3}{*}{ Pseudoletters } & Isolated & & 461.8 & 98.2 & 5.7 \\
\hline & Surrounded & Congruent & 468.5 & 95.5 & 5.1 \\
\hline & & Incongruent & 478.5 & 100.7 & 6.5 \\
\hline \multirow[t]{3}{*}{ Shapes } & Isolated & & 464.3 & 109.4 & 4.3 \\
\hline & Surrounded & Congruent & 463.9 & 105.2 & 5.2 \\
\hline & & Incongruent & 473.6 & 111.3 & 5.6 \\
\hline
\end{tabular}


Table 4

Stimulus Selections and Response Category Assignments to Individual Participants in Experiment 6

Selection 2

rounded targets, a $4 \times 2$ ANOVA with material (4) and congruence (congruent vs. incongruent surround) as factors resulted in a significant main effect for material $[F(3,72)=23.3, p<.01]$ and congruence $[F(1,24)=$ $13.1, p<.01]$ and a significant interaction $[F(3,72)=5.5$, $p<.01]$. For errors, only the interaction reached significance $[F(3,72)=3.3, p<.05]$.

Planned pairwise comparisons showed that for letters, the difference between congruent and incongruent surrounds was significant for RTs $(p<.05)$, but not for errors; for rotated letters, the difference was significant both for RTs $(p<.05)$ and for errors $(p<.01)$. Note, however, that whereas these differences reflected a negative congruence effect for letters, a positive congruence effect was obtained for rotated letters. A similar positive congruence effect was obtained for pseudoletters (for RTs, $p<.01$, and for errors, $p<.05$ ) and for shapes (for RTs, $p<.05$, and for errors, n.s.).

\section{Discussion}

As in the earlier experiments, positive congruence effects were obtained for target shapes, pseudoletters, and rotated letters. Negative congruence was obtained for letters. These results replicated the effects of the previous two ex-

Table 5

Condition Means in Experiment 4

\begin{tabular}{lllccc}
\hline \multirow{2}{*}{ Targets } & & & \multicolumn{2}{c}{ Reaction Time $(\mathrm{msec})$} & \\
\cline { 4 - 5 } Letters & Context & Congruence & $M$ & $S D$ & Error Rate (\%) \\
& Isolated & & 464.0 & 120.0 & 5.7 \\
& Surrounded & Congruent & 475.5 & 123.1 & 6.6 \\
\multirow{3}{*}{ Shapes } & & Incongruent & 468.5 & 119.1 & 6.4 \\
& Isolated & & 480.7 & 133.2 & 8.4 \\
& Surrounded & Congruent & 484.9 & 128.3 & 7.8 \\
& & Incongruent & 491.5 & 131.1 & 9.0 \\
\hline
\end{tabular}


periments. Of importance is the fact that positive congruence was obtained for rotated letters, even though they were now categorized as letters, as opposed to the previous experiment, where they were categorized as shapes. This is contrary to the response competition explanation of the negative congruence effects and in accordance with the feature integration explanation of congruence effects, which attributes the results to contrasting perceptual strategies.

\section{EXPERIMENT 4}

The present experiment provided a different way of testing the response competition against the feature integration explanation of negative congruence. In order to require the participants to distinguish letters from shapes, the previous experiments required an explicit classification into letters versus shapes. In the present experiment, this differentiation was done in an implicit way. Shapes and letters were assigned with equal frequency to each response category. For instance, one category was $A$ and rectangle, versus another, triangle and $L$. For each individual, stimuli were restricted to two pairs of stimuli: one pair of letters versus one pair of shapes. Different pairs were given in a balanced manner to the individual participants. It was important that letter and shape targets that were similar to each other, such as the $A$ and the triangle, were assigned to different categories. Because of this, there still was a need to distinguish letters and shapes, although they were now equally distributed across the response categories.

\section{Method}

Participants. The participants were 24 students ( 16 female) at the University of Leipzig, between 22 and 30 years of age, who either were paid or received course credit for their participation. All the participants had normal or corrected-to-normal vision.

Materials and Procedure. The materials and procedure were the same as those in the previous experiments, with the variation that different selections of letters and shapes were assigned to different response categories. The six selections used are shown in Table 4. Letters and shapes were equally distributed across both categories. Each individual participant was assigned to one of the selections, balancing the number of participants assigned to each selection, as well as the assignment of Response Categories 1 and 2 to the left and right response keys across participants. The participants received only trials containing the targets assigned to their response category. This means 4 (targets) $\times 3$ (isolated, congruent surrounding, or incongruent surrounding) unique trials, which were repeated 60 times in randomized order, yielding a total of 720 trials for each participant, which took about 25 min to complete.

\section{Results}

The criterion used to remove outliers was identical to that in the previous experiments. Of the total of 17,280 responses, $2.3 \%$ excluded cases were distributed equally over conditions. The data were analyzed for error rate and correct response RT.

Mean RTs and error rates are displayed in Table 5. The overall mean RT was $477 \mathrm{msec}(S D=126 \mathrm{msec})$ and ranged from $408 \mathrm{msec}(S D=90 \mathrm{msec})$ to $661 \mathrm{msec}$ $(S D=143 \mathrm{msec})$ for the individual participants. The mean error rate was $7.3 \%$ and ranged from $2.3 \%$ to $15.7 \%$ for the individual participants. No correlation was observed between individual mean error rates and mean RTs.

A first ANOVA was performed, including context (isolated, congruent surround, or incongruent surround) and material (letter vs. shape) as factors. Main effects were found to be significant for both factors $[F(2,46)=7, p<$ .01 , and $F(1,23)=7.5$, respectively; $p=.01]$. Letters were recognized more quickly $(469 \mathrm{msec})$ than shapes (486 msec) and isolated items more quickly (472 msec) than congruent and incongruent surrounded items, which did not differ $(480 \mathrm{msec})$. There was an interaction between these factors $[F(2,46)=4, p<.05]$, to be explored by the following post hoc analyses. No effects were found for error rates.

A $2 \times 2$ analysis with material and surroundings (isolated vs. surrounded) as factors showed significant main effects for material $[F(1,23)=7.5, p=.01]$ and for surroundings $[F(1,23)=11.5, p<.01]$. The interaction between these factors was not significant. The corresponding analysis for error rates revealed no effects at the 5\% level; however, there was a tendency for material $[F(1,23)=$ $3.9, p=.059$ ]; letters provoked fewer errors.

A post hoc design was applied to surrounded targets only to explore the effects of congruence. This $2 \times 2$ ANOVA used material and congruence (congruent vs. incongruent surround) as factors, which resulted in a significant main effect for material $[F(1,23)=6.8, p<.05]$, but not for congruence, whereas both factors interacted $[F(1,23)=$ $7, p=.01]$, due to a positive congruence effect for shapes and a negative congruence effect for letters. Whereas the congruence effect for letters was significant, it slightly failed to reach the $5 \%$ level for shapes (as revealed by pairwise comparisons). No effects were found for error rates.

\section{Discussion}

The present experiment showed a positive congruence effect for shapes (although only as a tendency at the $10 \%$ level) and a significant negative congruence effect for letters. The experiment replicated the results of the previous three experiments, despite the fact that the response categories were arbitrary and letters and shapes occurred with equal frequency within a response category. These results reduced the likelihood of a response competition explanation, in which the semantic label of the response category conflicts with the surrounding shape. The label of the response category is irrelevant to the feature integration strategies explanation of the result. The present results, therefore, confirm this explanation.

\section{EXPERIMENT 5}

In the previous experiment, a negative congruence was found again for letters despite the balance of letters and shapes in the response categories. This excludes an explanation in terms of response conflict for this effect. The feature integration explanation given for the effect assumes that a differentiation in processing strategy between 
Table 6

Condition Means in Experiment 5

\begin{tabular}{lllccc}
\hline \multirow{2}{*}{ Targets } & & & \multicolumn{2}{c}{ Reaction Time $(\mathrm{msec})$} & \\
\cline { 4 - 5 } & Context & Congruence & $M$ & $S D$ & Error Rate (\%) \\
\hline \multirow{2}{*}{ Letters } & Isolated & & 492.0 & 142.0 & 5.7 \\
& Surrounded & Congruent & 498.6 & 138.8 & 6.8 \\
& & Incongruent & 510.1 & 148.3 & 6.7 \\
& Isolated & & 529.8 & 147.4 & 10.3 \\
& Surrounded & Congruent & 537.3 & 147.3 & 10.8 \\
& & Incongruent & 550.9 & 156.3 & 13.1 \\
\hline
\end{tabular}

letters and shapes is needed. In the absence of such a differentiation, the shapes strategy is likely to be used in all cases, since it requires no inhibition of the surrounding shape. In the previous experiment, letters and similar shapes were in different response categories. When letters and visually similar shapes are together in the same response category, it is no longer necessary to distinguish the two. The task can then be performed simply by using a single strategy, in which stimuli are categorized on the basis of their shape. According to the feature integration view, this will result in the elimination of the negative congruence effect for letters. This prediction was tested in the present experiment.

\section{Method}

Participants. The participants were 26 students ( 22 female $)$ at the University of Leipzig, between 19 and 35 years of age, who either were paid or received course credit for their participation. All the participants had normal or corrected-to-normal vision.

Materials and Procedure. Only the stimuli from the letters and the shapes blocks were used. Letters and shapes trials were randomly intermixed. The response categories were as follows: Category $1=\mathrm{C}$ or circle, or L or rectangle; and Category $2=\mathrm{H}$ or square, or $\mathrm{A}$ or triangle. Given the visual similarity between $\mathrm{C}$ and circle, $\mathrm{L}$ and rectangle, $\mathrm{H}$ and square, and $\mathrm{A}$ and triangle, the response categories facilitated a strategy in which shape was taken as the category criterion. Prior to the experiment, a practice session was given with feedback, in which all the 24 possible stimuli occurred exactly once in random order. In the experiment, all the stimuli occurred 30 times, resulting in 720 trials. The experiment lasted approximately $25 \mathrm{~min}$.

\section{Results}

The same outlier rejection criteria as those in the previous experiments resulted in the removal of $2.1 \%$ of the total of 19,440 responses. These were equally distributed across the conditions. The data were analyzed for RT and error rate; for RT analyses, only correct responses were used.

Mean RTs and error rates are displayed in Table 6. The overall mean RT was $519 \mathrm{msec}(S D=148 \mathrm{msec})$ and ranged from $399 \mathrm{msec}(S D=69 \mathrm{msec})$ to $700 \mathrm{msec}(S D=$ $160 \mathrm{msec}$ ) for the individual participants. The mean error rate was $8.9 \%$ and ranged from $1.3 \%$ to $18 \%$ for the individual participants. No correlation was observed between the individual mean error rates and mean RTs.

A first $3 \times 2$ ANOVA was performed, including all factors and levels. The main effects for context (isolated, congruent surround, or incongruent surround) and material (letter vs. shape) were significant $[F(2,50)=22.5$ and $F(1,25)=77.1$, respectively, with $p<.01]$. Letters were responded to more quickly $(500 \mathrm{msec})$ than shapes $(539 \mathrm{msec})$, isolated more quickly than congruent, and congruent more quickly than incongruent, all significantly. No interaction was found. For error rates, main effects for context and material were found as well $[F(2,50)=$ 6.1 and $F(1,25)=39.5$, respectively; with $p<.01]$, the factors showed a weak interaction $[F(1,25)=3.6, p=$ $.004]$, caused by a higher error rate for incongruent shapes (see Table 6).

A $2 \times 2$ analysis with material and surroundings (isolated vs. surrounded) as factors showed significant main effects for material $[F(1,25)=73.1, p<.01]$ and for surroundings $[F(1,25)=26.1, p<.01]$. The interaction between these factors was not significant. The corresponding analysis for error rates revealed main effects for material $[F(1,25)=37.5, p<.01]$ and for surroundings $[F(1,25)=9, p=.01]$, but no interaction.

A post hoc analysis was applied to surrounded targets only to study the effects of congruence. This $2 \times 2$ ANOVA with material and congruence (congruent vs. incongruent surround) as factors resulted in significant main effects for material $[F(1,25)=79.1, p<.01]$ and congruence $[F(1,25)=18.2, p<.01]$. Congruent surrounded items were performed significantly more quickly for both letters and shapes. No interaction between these factors was found. For error rate, a main effect of material was found $[F(1,25)=36.7, p<.01]$, as well as an interaction between material and congruence $[F(1,25)=5.9, p<.05]$, again, due to a higher error rate for incongruent shapes, in comparison with other conditions that did not differ.

\section{Discussion}

In strong contrast with the previous experiments, a positive congruence effect was now obtained in all the conditions, for shapes as well as letters. This result was the consequence of a single manipulation, as compared with the previous experiment. Whereas in the previous experiment, response categories required a differentiation of letters and shapes, in the present experiment this was no longer the case, since visually similar letters and shapes were in the same response category. As a result, the task could be performed by encoding letters and shapes according to the same strategy. The result, therefore, was in accordance with the prediction of the feature integration approach. 
The absence of a negative congruence effect in these conditions could explain why such an effect is normally not obtained for letters in flanker experiments. This explanation assumes that flanker experiments are usually treated with a uniform strategy for shapes and letters, in cases in which the task does not require a differentiation. However, in the present experiment, letters and shapes were randomly intermixed, which facilitated a uniform strategy. This is usually not the case in flanker experiments. In the next experiment, therefore, letters and shapes were presented in blocked conditions.

\section{EXPERIMENT 6}

In order to extend the feature integration hypothesis to positive congruence effects normally obtained in the flanker task, it is of importance that a uniform strategy be used, even when letters and shapes are not randomly intermixed. The present experiment tested this hypothesis.

\section{Method}

Participants. The participants were 18 students ( 15 female) at the University of Leipzig, between 19 and 30 years of age, who either were paid or received course credit for their participation. All the participants had normal or corrected-to-normal vision.

Materials and Procedure. The stimuli were identical to those in Experiment 3. Trials were presented in four blocks consisting of letters, rotated letters, pseudoletters, and shapes. The blocks were presented in random order. Each block was preceded by a separate instruction in which two alternative response categories were given: for letters, Category $1=\mathrm{C}$ or $\mathrm{L}$, and Category $2=\mathrm{H}$ or $\mathrm{A}$; for rotated letters, Category $1=$ rotated $\mathrm{C}$ or rotated $\mathrm{L}$, and Category $2=$ rotated $\mathrm{H}$ or rotated $\mathrm{A}$; for pseudoletters, Category 1 = pseudo- $\mathrm{C}$ or pseudo-L, and Category 2 = pseudo-H or pseudo-A; for figures, Category 1 = circle or rectangle, and Category 2 = square or triangle. Response Categories 1 and 2 were mapped to left-right response keys in a manner that remained fixed within the blocks and was balanced across participants. The experimental trials of each block were preceded by 12 practice trials in which each of the unique stimuli was presented in randomized order. Each block consists of 216 trials in a randomized order, in which each unique stimulus occurred 18 times. The total experiment lasted approximately $35 \mathrm{~min}$.

\section{Results}

The same exclusion criteria as those in the previous experiments resulted in removing $2.2 \%$ of the total of 15,552 responses from the analysis. Removed cases were distributed equally across experimental conditions. Error rate and RT were analyzed; for RT analyses, only correct responses were used.

Mean RTs and error rates are displayed in Table 7. The overall mean RT was $442 \mathrm{msec}(S D=118 \mathrm{msec})$ and ranged from $350 \mathrm{msec}(S D=74.3 \mathrm{msec})$ to $553 \mathrm{msec}$ $(S D=143 \mathrm{msec})$ for the individual participants. The mean error rate was $8.2 \%$ and ranged from $1 \%$ to $15.3 \%$ for the individual participants. No correlation was observed between individual mean error rates and mean RTs.

A first $3 \times 4$ ANOVA was performed, including all factors and levels. The main effects for context (isolated, congruent, or incongruent) and material (letter, rotated letter, pseudoletter, or shape) were significant $[F(2,34)=18.7$, $p<.01$, and $F(3,51)=13.7$, respectively]. No interaction was found. Individuals responded more quickly to isolated items $(446 \mathrm{msec})$, followed by the congruent surrounded items $(452 \mathrm{msec})$, and needed the most time for the incongruent surrounded items ( $459 \mathrm{msec})$. Letters $(417 \mathrm{msec})$ and rotated letters $(428 \mathrm{msec})$ were responded to most quickly, without a significant difference between them, followed by shapes ( $508 \mathrm{msec}$ ) and then by pseudoletters (454 msec), all of which differed significantly. For error rate analyses, only the main effect for context was found to be significant $[F(2,34)=5.8, p<.05]$. The error rate was higher for incongruent surrounded items $(9.3 \%)$ than for congruent surrounded (7.4\%) and isolated (7.8\%) items; the latter two did not differ.

A $4 \times 2$ analysis with material (4) and surroundings (isolated vs. surrounded) as factors showed significant main effects for material $[F(3,51)=13.3, p<.01]$ and for surroundings $[F(1,17)=19.6, p<.01]$. The interaction between these factors was not significant. The corresponding analysis for error rates revealed no effects.

A post hoc design was applied to surrounded targets only to explore the effects of congruence. This $4 \times 2$ ANOVA

Table 7

Condition Means in Experiment 6

\begin{tabular}{|c|c|c|c|c|c|}
\hline \multirow[b]{2}{*}{ Targets } & \multirow[b]{2}{*}{ Context } & \multicolumn{4}{|c|}{ Reaction Time (msec) } \\
\hline & & Congruence & $M$ & $S D$ & Error Rate $(\%)$ \\
\hline \multirow[t]{3}{*}{ Letters } & Isolated & & 413.0 & 124.3 & 7.4 \\
\hline & Surrounded & Congruent & 416.6 & 129.8 & 6.8 \\
\hline & & Incongruent & 421.1 & 123.3 & 7.8 \\
\hline \multirow[t]{3}{*}{ Rotated letters } & Isolated & & 420.3 & 117.7 & 7.2 \\
\hline & Surrounded & Congruent & 426.2 & 122.3 & 7.4 \\
\hline & & Incongruent & 436.3 & 120.3 & 10.6 \\
\hline \multirow[t]{3}{*}{ Pseudoletters } & Isolated & & 448.2 & 121.8 & 7.4 \\
\hline & Surrounded & Congruent & 457.0 & 121.3 & 6.9 \\
\hline & & Incongruent & 459.7 & 123.6 & 9.6 \\
\hline \multirow[t]{3}{*}{ Shapes } & Isolated & & 494.9 & 145.9 & 9.2 \\
\hline & Surrounded & Congruent & 499.7 & 138.6 & 8.4 \\
\hline & & Incongruent & 512.7 & 140.6 & 9.4 \\
\hline
\end{tabular}


with material (4) and congruence (congruent vs. incongruent surroundings) as factors resulted in significant main effects for material $[F(3,51)=14.3, p<.01]$ and for congruence $[F(1,17)=16.8, p<.01]$. No interaction was found. For errors, only the main effect of congruence reached significance $[F(1,17)=10.1, p=.01]$. The participants responded more quickly and made fewer errors for congruent surrounded items (452 msec; $7.4 \%$ ) than for incongruent surrounded items (459 msec; 9.3\%).

Post hoc pairwise comparisons showed that RTs and error rates for congruent surrounded rotated letters were significantly lower than those for incongruent ones. As a tendency, this effect was also observed for letters. For pseudoletters, RTs, but not error rates, and, for shapes, error rates, but not RTs, showed a significant positive congruence effect.

\section{Discussion}

Across the material conditions in the present experiment, a positive congruence effect was obtained (although it failed to reach significance for letters). According to the feature integration strategies explanation, this is because the task does not require the differentiation of letters and shapes and both can be classified using a uniform strategy. The result contrasts with those in Experiments 1-4 but replicates that in the previous experiment, in which letters and shapes were randomly intermixed. According to our interpretation, the shapes strategy prevailed even when letters and shapes were presented in separate blocks. This may have seen the result of the absence of the need to inhibit feature integration in this strategy. This means that the present experiment explains why a negative congruence effect is not normally obtained in flanking experiments using letters. The nonletter strategy appears to be the default strategy and is applied even to letters when a differentiation of letters and nonletters is not required by the task. In this case, positive congruence effects are obtained uniformly within letters and shapes.

\section{COMPARING EXPERIMENTS 5 AND 6}

The stimuli in two blocks in Experiment 6 correspond to the stimuli that were randomly intermixed in Experiment 5. Assuming that in both experiments, the same perceptual strategy (the shape strategy) has been followed, and ignoring for this analysis the effects of practice and history, we may compare the results on the blocked conditions for letters and shapes in Experiment 5 with those

Table 8

Comparison Across Experiments 4 and 5

\begin{tabular}{clcc}
\hline Targets & Condition & Blocked & Random \\
\hline Letters & Isolated & 413.0 & 492.0 \\
& Congruent & 416.6 & 498.6 \\
& Incongruent & 421.1 & 510.1 \\
Shapes & Isolated & 494.9 & 529.8 \\
& Congruent & 499.7 & 537.3 \\
& Incongruent & 512.7 & 550.9 \\
\hline
\end{tabular}

in Experiment 6, where these were randomly intermixed. A $3 \times 2 \times 3$ ANOVA of context (isolated vs. congruent vs. incongruent) $\times$ material (letters vs. shapes) $\times$ blocking (blocked, from Experiment 6, vs. random, from Experiment 5) resulted in main effects of context $[F(2,84)=$ $33.1, p<.01]$ and material $[F(1,42)=73.2, p<.01]$. There was an interaction of material and blocking $[F(1,42)=$ $12.8, p<.01]$. According to Table 8 , the result was due to a large blocking advance for letters, combined with a minor one for shapes. No other effects approached significance.

Although these analyses should be taken with a grain of salt - we should be aware, for instance, of the effects of practice and fatigue that differed between Experiments 5 and 6-these differences are most likely to lead to Type II errors in the blocking variable. In this respect, the interaction of blocking and material is of interest; letters benefit from blocking, but shapes do not (or not to the same extent).

Of importance to our central hypothesis is the absence of any interaction involving the context factor. This illustrates that as long as no differentiation of letters and shapes is needed, it does not matter whether they occur intermixed or not. Or in other words, the choice of perceptual strategy depends on task demands, not on presentation conditions.

\section{GENERAL DISCUSSION}

In six experiments, we investigated the task specificity of congruence effects in letter and nonletter perception. We found that letters surrounded by similar, or congruent, shapes received slower and less accurate responses than did those surrounded by incongruent ones. This negative congruence effect contrasts with the positive congruence effects obtained for nonletters, such as geometrical shapes, rotated letters, or pseudoletters.

An explanation of this effect in terms of lateral masking is unlikely. Foveal presentation was used, and moreover, performance in the preferred surround condition (congruent for shapes, including pseudoletters and rotated letters, and incongruent for letters) was usually just as good as when the targets were presented in isolation.

Negative congruence effects previously obtained have been attributed to target selection (Bavelier et al., 2000) or feature integration (van Leeuwen \& Bakker, 1995). The first explanation predicts that the effect will go away when simple stimuli are used. In the present experiments, very simple stimuli with clear segmentation cues was used. This is confirmed by the observation that incongruently surrounded letters had RTs and error rates similar to those for isolated ones. In addition, RTs were generally shorter, and fewer errors were made, for letters than for shapes. Because of this, the negative congruence effect is not likely to have resulted from target selection difficulties as such.

The result may be ascribed to different perceptual integration strategies for shape and letter perception. Whereas shape perception preferably integrates the targets with 
(the features of) their surrounding shapes (leading to positive congruence effects), this is not preferred for letter perception (leading to negative effects). Thus, the task interacts with the material either to promote feature integration and global processing (in which case, positive congruency effects are seen) or to promote disjunction and separate processing (in which case, negative congruency effects are seen). This explanation extends the feature integration explanation of congruence effects given by van Leeuwen and Bakker (1995). The difference in strategy should be understood as a different treatment of relational features, such as symmetry, collinearity, parallelism, and closure. For coding shapes, the axes of symmetry may be considered an important reference system (e.g., Pashler, 1990). Hence, encoding will preferably integrate the local features of the figure representations that emphasize these global features. Congruent surrounding context enhances the perception of these relational features (Krueger, 1973).

This may be exactly why congruent surroundings are less preferred for letter processing. Symmetry-for instance, between $b$ and $d$ or $p$ and $q$ - may even be confusing, as is evident for beginning or dyslexic readers (e.g., Brendler \& Lachmann, 2001; Lachmann \& Geyer, 2003; Orton, 1925). The proposed explanation, therefore, is that in the encoding of the letters, these global perceptual features are suppressed in favor of an encoding in terms of a more abstract letter identity code (Bigsby, 1988). The suppression is easier with incongruent surrounding shapes than with congruent ones. This hypothesis explains why negative congruence effects are obtained for letters. In this understanding, the difference in processing strategies between letters and nonletters observed in our experiments was a natural consequence of the existence of a separate perceptual strategy for symbols normally used in reading.

Letters that are initially processed independently are integrated, subsequently, with other letters to form words, and lexical knowledge can facilitate the identification of a target letter, as in the word superiority effect (Baron \& Thurston, 1973; Krueger, 1975; Reicher, 1969). In other words, in reading strategies, the integration takes place at the level of a phonological or abstract letter identity code (Bigsby, 1988), but not at the level of a geometric shape code (Krueger, 1975; Krueger \& Shapiro, 1979). In this respect, Huckauf et al.'s (1999) result is interesting because it involves a (comparatively minor) dissociation between letters and nonletters in lateral-masking conditions. In their study, rotated letters, for instance, produced more flanker inhibition than did letters, which was ascribed to an absence of a letter identity code.

Such an explanation may shed light on reading disturbances. A certain group of dyslexics might be characterized by an inability to process letters in the specific way that skilled reading requires. These are most likely to fall prey to symmetry errors, such as confusing $b$ and $d$. In this respect, they may find themselves in a situation similar to Huckauf et al.'s (1999) rotated letter conditions. This hypothesis is currently under investigation (Lachmann, 2002; Lachmann \& Geyer, 2003). If these effects play a role, the aim of further studies could be to examine the role of flankers in reading. In order to draw conclusions regarding the impact of flanking on reading, words will have to be used.

The letter identity code may be the preferred format for encoding single letters before integrating them into encodings on the word level. The word superiority effect (Baron \& Thurston, 1973; Krueger, 1975; Reicher, 1969) shows that letters in word contexts are processed preferably in terms of word, rather than isolated letter, morphology. In accordance with this observation, letters in the context of other letters show a positive congruence effect (Eriksen \& Eriksen, 1974). One reason, therefore, why negative congruence effects have not been observed more frequently is that in flanker congruence studies, usually, letters are flanked with letters.

Another reason why negative congruence effects are rare in flanker studies is that the displays used are relatively simple. Display complexity (Bavelier et al., 2000; van Leeuwen \& Bakker, 1995) may be a reason to prefer the suppression of feature integration, since it facilitates serial scanning (Hogeboom \& van Leeuwen, 1997).

A third reason appears to be a strategy preference that is intrinsic to the flanker task. In both search (von Grünau, Dubé, \& Galera, 1994) and nonsearch (Mason, 1982; Zegarra-Moran \& Geiger, 1993) conditions, the perception of letters and figures has been compared, but to our knowledge, no clear dissociation between letters and shapes, as in the present experiments, has previously been obtained (although Huckauf et al., 1999, reported larger effects of lateral masking for nonletters than for letters). According to the integration strategies hypothesis, this is because these experiments fail to require their participants to distinguish between letters and shapes. When this is not required, as in our Experiments 5 and 6, where similarshaped letters and nonletters were grouped together in the same response category, the negative congruence effect for letters disappeared, and a positive congruence effect was obtained uniformly for letters and shapes. This means that for the same letter stimuli, positive or negative congruence depends on the task. Obviously, there is no intrinsic property of letters that makes them different from nonletter shapes, so if the task does not require the perceiver to distinguish them, they can be treated by the same perceptual strategy. Experiment 6 showed that this effect remained (although it was less pronounced) when letters and nonletters were blocked, instead of randomly intermixed. It may therefore be concluded that the nonletter perception strategy is the default strategy in flanker task conditions and is, therefore, normally used for letters as well. Flanker tasks usually do not require participants to distinguish letters and shapes, and this completes the set of reasons why the effects presently observed are lacking in the literature.

Evidence was obtained in two experiments against the ascription of the negative congruence effect to responserelated processes. Such an explanation was initially enabled by an imbalance in the response categories of Experiments 1 and 2. In principle, in these experiments, the effect could have been due to the fact that the tendency to give a shape 
response was reinforced for letters that were surrounded by shapes when these shapes were similar to the letters. In Experiment 3, however, it was revealed that rotated letters show positive congruence effects (as they did in Experiment 2), despite being classified as letters. In Experiment 4 , letter versus shape classification was no longer used. Instead, letters and shapes were equally distributed across the response categories, but similar letters and nonletters that were similar in shape were placed in different response categories, requiring the participants still to distinguish them (different from Experiments 5 and 6). Negative congruence effects were still obtained in this case.

We do not wish to deny the occurrence of response conflicts in our study. In one condition, there was an increased number of errors when rotated letters were used as shapes, suggesting a response conflict. This may show that some participants experienced some difficulty in treating the rotated letters as shapes. It seems that one perceptual processing strategy does not completely suppress the other. Probably, both a perceptually integrating shapes processing and a nonintegrating letters processing run in parallel in different hemispheres (Bedson \& Turnbull, 2002), with one receiving priority over the other, depending on the domain.

Perhaps the clearest demonstration that, despite their origin in early perception, congruence effects depend on the task, and not on the physical characteristics of the stimuli alone, could be obtained by comparing the results in Experiment 4 with those in Experiments 5 and 6. In Experiment 4, negative and, in Experiments 5 and 6, positive congruence effects were obtained for the same material.

These results suggest that perceptual feature integration processes (Pomerantz \& Pristach, 1989) are actively suppressed in the case of letter perception. This interpretation is in accordance with a dynamic, interactive approach to visual information processing, in which perceptual binding determines the content of processing but, at the same time, there is strategic control over the perceptual binding process. This control is nonspecific and determines the degree to which integration into higher order, global features occurs. Stimulus features competing with the preferred strategy lead to increased RTs and error rates. This assumption may explain negative congruence for letters. The attractive aspect of this explanation is that it brings these effects in line with word superiority effects and object superiority effects observed in the flanker task. Moreover, this assumption can also explain, in principle, the occurrence of normal congruence effects for letters and shapes. Yet we acknowledge that congruence effects may appear for reasons other than feature integration strategies. The present approach wishes to complement, rather than replace, accounts of flanking based on crowding, selective attention, and response competition.

\section{REFERENCES}

Banks, W. P., Bodinger, D., \& Illige, M. (1974). Visual detection accuracy and target-noise proximity. Bulletin of the Psychonomic Society, 4, 411-414.
Banks, W. P., \& Prinzmetal, W. (1976). Configurational effects in visual information processing. Perception \& Psychophysics, 19, 361-367.

Baron, J., \& Thurston, I. (1973). An analysis of the word-superiority effect. Cognitive Psychology, 4, 207-228.

Bavelier, D., Deruelle, C., \& Proksch, J. (2000). Positive and negative compatibility effects. Perception \& Psychophysics, 62, 100-112.

Bedson, E., \& Turnbull, O. H. (2002). Hemispheric asymmetry for global and local processing: Language is less important than one might think. Brain \& Cognition, 48, 272-277.

BESNER, D. (2001). The myth of ballistic processing: Evidence from Stroop's paradigm. Psychonomic Bulletin \& Review, 8, 324-230.

Bigsby, P. (1988). The visual processor module and normal adult readers. British Journal of Psychology, 79, 455-469.

BJorK, E. L., \& MurraY, J. T. (1977). On the nature of input channels in visual processing. Psychological Review, 84, 472-484.

Bouma, H. (1970). Interaction effects in parafoveal letter recognition. Nature, 226, 177-178.

BRENDLER, K., \& LACHMANN, T. (2001). Letter reversals in the context of the functional coordination deficit model. In E. Sommerfeld, R. Kompass, \& T. Lachmann (Eds.), Proceedings of the International Society for Psychophysics (pp. 308-313). Lengerich, Berlin: Pabst.

Briand, K. A. (1994). Selective attention to global and local structure of objects: Alternative measures of nontarget processing. Perception \& Psychophysics, 55, 562-574.

BROOKS A., \& VAN DER ZWAN, R. (2002). The role of on- and off-channel processing in the detection of bilateral symmetry. Perception, 3, 10611072.

Cepeda, N. J., \& Kramer, A. F. (1999). Strategic effects on objectbased attentional selection. Acta Psychologica, 103, 1-19.

Chung, S. T., Levi, D. M., \& LegGe, G. E. (2001). Spatial-frequency and contrast properties of crowding. Vision Research, 41, 1833-1850.

Davis, E. T., Shikano, T., Peterson, S. A., \& Keyes, M. R. (2003). Divided attention and visual search for simple versus complex features. Vision Research, 43, 2213-2232.

DEACON, T. W. (2000). Evolutionary perspectives on language and brain plasticity. Journal of Communication Disorders, 33, 273-291.

Di Lollo, V., EnNS, J. T., \& Rensink, R. A. (2000). Competition for consciousness among visual events: The psychophysics of reentrant visual processes. Journal of Experimental Psychology: General, $\mathbf{1 2 9}_{2}$ 481-507.

DUNCAN, J. (1984). Selective attention and the organization of visual information. Journal of Experimental Psychology: General, 113, 501-517.

Duncan, J. (1985). Visual search and visual attention. In M. I. Posner \& O. S. M. Marin (Eds.), Attention and performance XI (pp. 85-106). Hillsdale, NJ: Erlbaum.

DunCAN, J., \& Humphreys, G.W. (1989). Visual search and stimulus similarity. Psychological Review, 96, 433-458.

Egeth, H. E., \& SANTEE, J. L. (1981). Conceptual and perceptual components in interletter inhibition. Journal of Experimental Psychology: Human Perception \& Performance, 7, 506-517.

ELEY, M. G. (1982). Identifying rotated letter-like symbols. Memory \& Cognition, 10, 25-32.

ERIKSEN, B. A., \& ERIKSEN C. W. (1974). Effects of noise letters upon the identification of a target letter in a nonsearch task. Perception \& Psychophysics, 16, 143-149.

EsTES, W. K. (1972). Interactions of signal and background variables in visual processing. Perception \& Psychophysics, 12, 278-286.

EstEs, W. K. (1982). Similarity-related channel interactions in visual processing. Journal of Experimental Psychology: Human Perception \& Performance, 8, 353-382.

Field, D. J., HAYES, A., \& Hess, R. F. (1993). Contour integration by the human visual system: Evidence for a local "association field." Vision Research, 33, 173-193.

Fox, E. (1998). Perceptual grouping and visual selective attention. Perception \& Psychophysics, 60, 1004-1021.

Freeman, E., Driver, J., Sagi, D., \& ZhaOPing, L. (2003). Top-down modulation of lateral interactions in early vision: Does attention affect integration of the whole or just perception of the parts? Current Biology, 13, 985-989.

FrIEDERICI, A. D., \& LachmanN, T. (2002). From language to reading and reading disability: Cognitive functions and their neural basis. In 
E. Witruk, A. D. Friederici, \& T. Lachmann, Basic functions of language, reading, and reading disability (pp. 9-21). Boston: Kluwer.

Garner, W. R., \& Clement, D. E. (1963). Goodness of pattern and pattern uncertainty. Journal of Verbal Learning \& Verbal Behavior, 2 446-452.

GHIRARDELLI, T. G., \& EgETH, H. E. (1998). Goal-directed and stimulusdriven attention in cross-dimensional texture segregation. Perception \& Psychophysics, 60, 826-838.

Gong, P., Nikolaev, A., \& VAN Leeuwen, C. (2003). Scale-invariant fluctuations of the dynamical synchronization in human brain electrical activity. Neuroscience Letters, 336, 33-36.

GreEnberg, S. N., \& KRUEGER, L. E. (1983). Effect of letter orientation and sequential redundancy on the speed of letter search. Memory \& Cognition, 11, 181-191.

HagenaAr, R., \& van DeR HeiJden, A. H. (1986). Target-noise separation in visual selective attention. Acta Psychologica, 62, 161-176.

Hazeltine, E., Poldrack, R., \& Gabrieli, J. D. (2000). Neural activation during response competition. Journal of Cognitive Neuroscience, 12(Suppl. 2), 118-129.

HOGEBOOM, M., \& VAN LEEUWEN, C. (1997). Visual search strategy and perceptual organization covary with individual preference and structural complexity. Acta Psychologica, 95, 141-164.

Huckauf, A., Heller, D., \& NazIR, T. A. (1999). Lateral masking: Limitations of the feature interaction account. Perception \& Psychophysics, 61, 177-189.

JosePh, J. E., Gathers, A. D., \& PiPer, G. A. (2003). Shared and dissociated cortical regions for object and letter processing. Cognitive Brain Research, 17, 56-67.

JuLESZ, B. (1966). Binocular disappearance of monocular symmetry. Science, 153, 657-658.

KANIZSA, G. (1985). Seeing and thinking. Acta Psychologica, 59, 23-33.

KIMchI, R. (1994). The role of wholistic/configural properties versus global properties in visual form perception. Perception, 23, 489-504.

Kovacs, I., \& Julesz, B. (1993). A closed curve is much more than an incomplete one: Effect of closure in figure-ground segmentation. Proceedings of the National Academy of Sciences, 15, 7495-7497.

Kramer, A. F., \& JaCobson, A. (1991). Perceptual organization and focused attention: The role of objects and proximity in visual processing. Perception \& Psychophysics, 50, 267-284.

KRUEGER, L. E. (1973). Effect of irrelevant surrounding material on speed of same-different judgement of two adjacent letters. Journal of Experimental Psychology, 98, 252-259.

KRUEGER, L. E. (1975). The word-superiority effect: Is its locus visualspatial or verbal? Bulletin of the Psychonomic Society, 6, 465-468.

Krueger, L. E., \& Shapiro, R. G. (1979). Letter detection with rapid serial visual presentation: Evidence against word superiority at feature extraction. Journal of Experimental Psychology: Human Perception \& Performance, 5, 657-673.

LACHMANN, T. (2002). Reading disability as a deficit in functional coordination. In E. Witruk, A. D. Friederici, \& T. Lachmann (Eds.), Basic functions of language, reading, and reading disability (pp. 165-198). Boston: Kluwer.

LACHMANN, T., \& GeYER, T. (2003). Letter reversals in dyslexics: Is the case really closed? A critical review and conclusions. Psychology Science, 45 (Suppl. 1), 50-70.

LaVIE, N. (1995). Perceptual load as a necessary condition for selective attention. Journal of Experimental Psychology: Human Perception \& Performance, 21, 451-468.

LEAT, S. J., LI, W., \& EPP, K. (1999). Crowding in central and eccentric vision: The effects of contour interaction and attention. Investigative Ophthalmology \& Visual Science, 40, 504-512.

MASON, M. (1982). Recognition time for letters and nonletters: Effects of serial position, array size, and processing order. Journal of Experimental Psychology: Human Perception \& Performance, 8, 724-738.

Mewhort, D. J., Marchetti, F. M., \& CAMPBell, A. J. (1982). Blank characters in tachistoscopic recognition: Space has both a symbolic and a sensory role. Canadian Journal of Psychology, 36, 559-575.

MiLLER, J. (1991). The flanker compatibility effect as a function of visual angle, attentional focus, visual transients, and perceptual load: A search for boundary conditions. Perception \& Psychophysics, 49, 270-288.
Nakatani, H., Khalilov, I., Gong, P., \& van Leeuwen, C. (2003). Chaotic determism in giant depolarizing potentials. Physics Letters A, 319, 167-172.

ORTON, S. T. (1925). "Word-blindness" in school children. Archives of Neurology \& Psychiatry, 14, 581-615.

Paquet, L., \& Lortie, C. (1990). Evidence for early selection: Precuing target location reduces interference from same-category distractors. Perception \& Psychophysics, 48, 382-388.

PASHLER, H. (1990). Coordinate frame for symmetry detection and object recognition. Journal of Experimental Psychology: Human Perception \& Performance, 16, 150-163.

PoLAT, U., \& SAGI, D. (1993). Lateral interactions between spatial channels: Suppression and facilitation revealed by lateral masking experiments. Vision Research, 33, 993-999.

Pomerantz, J. R., \& Pristach, E. A. (1989). Emergent features, attention, and perceptual glue in visual form perception. Journal of Experimental Psychology: Human Perception \& Performance, 15, 635-649.

REICHER, G. M. (1969). Perceptual recognition as a function of meaningfulness of stimulus material. Journal of Experimental Psychology, 81, 275-280.

RENSINK, R. A., \& EnNs, J. T. (1995). Preemption effects in visual search: Evidence for low-level grouping. Psychological Review, 102, 101-130.

Ross, W. D., Grossberg, S., \& Mingolla, E. (2000). Visual cortical mechanisms of perceptual grouping: Interacting layers, networks, columns, and maps. Neural Networks, 13, 571-588.

Rouder, J. N., \& KING, J. W. (2003). Flanker and negative flanker effects in letter identification. Perception \& Psychophysics, 65, 287-297.

Rueckl, J. G., SuZuki, S., \& YeH, S.-L. (1991). On the locus of redundancy effects in a letter-detection task. Perception \& Psychophysics, $\mathbf{4 9}_{2}$ 412-421.

SANDERS, A. F., \& LAMERs, J. M. (2002). The Eriksen flanker effect revisited. Acta Psychologica, 10, 41-56.

Stins, J. F., \& VAN LEEUWEN, C. (1993). Context influence on the perception of figures as conditional upon perceptual organization strategies. Perception \& Psychophysics, 53, 34-42.

STroop, J. R. (1935). Studies of interference in serial verbal reactions. Journal of Experimental Psychology, 18, 643-662.

ToET, A., \& LEVI, D. M. (1992). Spatial interaction zones in the parafovea. Vision Research, 32, 1349-1357.

Treisman, A. M., \& GelA attention. Cognitive Psychology, 12, 97-136.

VAN DER LuBBE, R. H., \& KeUSS, P. J. (2001). Focused attention reduces the effect of lateral interference in multi-element arrays. Psychological Research, 65, 107-118.

VAN LEEUWEN, C., \& BAKKER, L. (1995). Stroop can occur without Garner interference: Strategic and mandatory influences in multidimensional stimuli. Perception \& Psychophysics, 57, 379-392.

van Leeuwen, C., Steyvers, M., \& NoOter, M. (1997). Stability and intermittency in large-scale coupled oscillator models for perceptual segmentation. Journal of Mathematical Psychology, 41, 319-344.

van LeEuwen, C., \& VAN DEN HoF, M. (1991). What has happened to Prägnanz? Coding, stability, or resonance. Perception \& Psychophysics, 50, 435-448.

voN GrünAu, M., Dubé, S., \& Galera, C. (1994). Local and global factors of similarity in visual search. Perception \& Psychophysics, $\mathbf{5 5}_{2}$ 575-592.

WOLFE, J. M., \& CAVE, K. R. (1999). The psychophysical evidence for a binding problem in human vision. Neuron, 24, 11-17.

Wolfe, J. M., Cave, K. R., \& FranzeL, S. L. (1989). Guided search: An alternative to the feature integration model for visual search. Journal of Experimental Psychology: Human Perception \& Performance, $\mathbf{1 5}$, 419-433.

Zegarra-Moran, O., \& Geiger, G. (1993). Visual recognition in the peripheral field: Letters versus symbols and adults versus children. Perception, 22, 77-90.

(Manuscript received August 10, 2002; revision accepted for publication October 18, 2003.) 